\title{
Cognitive Dysfunction
}

National Cancer Institute

\section{Source}

National Cancer Institute. Cognitive Dysfunction. NCI Thesaurus. Code C46083.

Interference or disruption of cog nitive processes. This term encompasses a large

number of problems and issues associated with intellectual functioning and information

processing. 2005 